\title{
Consumers' evaluation of imported organic food products: The role of geographical distance
}

\section{Introduction}

The global organic food market has grown rapidly over the last decade (Sahota, 2018), passing EUR 80 billion in 2016 (Willer \& Lernoud, 2018). Germany is the world's second largest market for organic products and the largest in Europe, amounting to EUR 9.5 billion in 2016, about 30 percent of total European organic retail sales (Willer \& Lernoud, 2018). Despite the organic agricultural area being expanded and an increase in the number of organic producers (BÖLW, 2017), the demand for organic food has grown substantially faster than domestic production and supply, in Germany as in many other countries. This supply deficit has led to high import shares for many organic food products (Willer \& Lernoud, 2018).

Hence, consumers in Germany (as in many other countries) have access to a variety of organic food products from different countries, both close by and farther away. Presumably, they evaluate product quality and develop preferences not only based on the organic labelling, but also based on other quality cues, including country of origin (COO) (Newman, Turri, Howlett, \& Stokes, 2014; Thøgersen, Pedersen, \& Aschemann-Witzel, 2018). Consumers' associations to a country, and the inferences generated by a COO label, are shaped through experience with the country and through media and other sources of information about the nature of its people, locations, products and services and other things that the country is known for (e.g., Ahmed \& d'Astous, 2008; Iyer \& Kalita, 1997; Verlegh \& Steenkamp, 1999).

Most studies of $\mathrm{COO}$ effects focus on consumer preferences for domestic versus imported, also regarding organic foods. Consistent with the existence of a general "domestic country bias" (Balabanis \& Diamantopoulos, 2004), studies in a variety of national contexts, focusing on different products, have found that consumers prefer domestic to imported organic products (Dransfield et al., 2005; Schjøll, 2017; Xie, Gao, Swisher, \& Zhao, 2016). However, some studies in developing and middle-income countries found that consumers prefer at least some foreign origins to domestic 
29

- usually an economically more developed country (e.g., Australian beef in China, cf. Ortega, Hong, Wang, \& Wu, 2016).

Research on consumer origin preferences when choosing between imported organic products from different countries is scarce. Onozaka and Mcfadden (2011) and Xie et al. (2016) found that US consumers prefer organic tomatoes, respectively broccoli from Canada to Mexico, and broccoli from Mexico to China (Xie et al., 2016). Schjøll (2017) found that Norwegian consumers prefer minced veal from Denmark to Poland and Ortega et al. (2016) that consumers in Beijing, China, prefer beef from Australia to US.

None of these actually investigated the reasons for consumers' preferences regarding foreign origin. However, many inferred, or speculated, what the main causes of consumer preferences might be. For example, Schjøll (2017) suggested familiarity, geographical proximity and cultural similarity. Others have inferred that $\mathrm{COO}$ effects are influenced by geographical and socio-cultural distance (e.g., Lazzarini, Visschers, \& Siegrist, 2017), and that geographical distance is important because it influences consumer familiarity with a foreign country and its products (Ahmed \& d'Astous, 2008). However, none of these presented empirical evidence as to why consumers value some foreign origins of organic foods more than others. Instead, conclusions on this issue is limited to inferences and speculation based on a small selection of countries. Since any selection of countries differ on a host of characteristics, this method does not allow one to isolate the effect of one of these, such as geographical distance.

Further evidence suggesting that geographical distance matters comes from research on consumer preferences for local food (Feldmann \& Hamm, 2015; Grebitus, Lusk, \& Nayga, 2013), compared to both domestic and imported products (Hempel \& Hamm, 2016a, 2016b). For example, Hempel and Hamm (2016b) found that German consumers prefer local (radius of $50 \mathrm{~km}$ ) conventional food to organic food from outside their local region (domestic, from a neighbouring country, or from a non-EU country). However, in this stream of research it is not possible to disentangle distance from other factors that might be involved in preferences for local, such as sensory appeal and price (Hasselbach \& Roosen, 2015) or support of the local economy (Grebitus et al., 2013).

Research on both consumer preferences for organic and COO are thriving (Aschemann-Witzel \& Zielke, 2017; Hemmerling, Hamm, \& Spiller, 2015; Newman et al., 2014), but research on their combined effect is scarce (Thøgersen, Pedersen, Paternoga, Schwendel, \& Aschemann-Witzel, 2017). The COO serves as a cue to product quality for consumers (Verlegh \& Steenkamp, 1999), 
60 but its impact on consumer evaluation and choice tends to be attenuated if there are other quality cues available as well (Newman et al., 2014). It has been argued that this reflects a decreasing marginal effect of additional, consistent cues to quality (Thøgersen et al., 2018). Consumers also use organic labels as a cue to product quality (e.g., Hemmerling et al., 2013; Loebnitz \& Aschemann-Witzel, 2016; Marian \& Thøgersen, 2013), which suggests that consumers should be less sensitive to the $\mathrm{COO}$ when choosing between organic and conventional food products (e.g., Lazzarini et al., 2017; Schjøll, 2017).

However, there is also research suggesting that the $\mathrm{COO}$ might be more important to consumers when choosing between organic and conventional food (e.g., Nuttavuthisit \& Thøgersen, 2017). Organic is a credence characteristic, and organic food production is generally perceived as more environmentally friendly than conventional (e.g., Lazzarini et al., 2017; Tobler, Visschers, \& Siegrist, 2011). These characteristics are likely to increase both consumer uncertainty and involvement in the choice, which might make them more attentive to other quality cues, including the COO of organic products (Nuttavuthisit \& Thøgersen, 2017).

A few studies assessed the joint effect of $\mathrm{COO}$ and organic labelling by means of choice experiments. A significant, positive interaction between various foreign country labels and organic labelling was found in USA for broccoli (Xie et al., 2016), apples and tomatoes (Onozaka \& Mcfadden, 2011) and in Norway for minced veal (Schjøll, 2017). However, a negative interaction was found between Australian origin and organic labelling in Beijing, China, for beef (Ortega et al., 2016). Finally, a study using samples from three European and two Asian countries found both positive and negative interactions between organic labelling and foreign origin for milk and pork chops (Thøgersen et al., 2018). The different signs of these interactions seem to be linked to consumers' evaluation of the foreign origin. Specifically, it seems that an organic label reduces the positive effect of a preferred $\mathrm{COO}$ and the negative effect of an undesirable COO.

Research on consumers' evaluation of foreign countries often use the term "country image" (Josiassen, Lukas, Whitwell, \& Assaf, 2013; Roth \& Diamantopoulos, 2009). Much research on country image in the food area discusses specific country-product matches (like Columbian coffee) (Kotler \& Gertner, 2002). Another large stream of research discusses the level of economic development as a general image factor (Manrai, Lascu, \& Manrai, 1998; Verlegh \& Steenkamp, 1999). This stream also includes research on organic food products. A key finding in this research, not limited to (organic) food (e.g., Verlegh \& Steenkamp, 1999), is that consumers generally prefer 
91 products from an economically more developed country to products from a less developed country 92 (Nuttavuthisit \& Thøgersen, 2018; Onozaka \& Mcfadden, 2011; Thøgersen et al., 2018). However, 93 this research is obviously mute about how and why consumer preferences differ between countries 94 at the same level of economic development, which accounts for a large share of international trade 95 in organic food. ${ }^{1}$

96 In sum, it seems that geographical distance matters as reflected, for example, in locally produced 97 food being preferred to food produced farther away and products from neighbouring countries being 98 preferred to products from more distant countries. However, there is a lack of direct (as opposed to indirect or inferential) evidence on the importance of geographical distance and why geographical distance matters to consumers. This lack of evidence is not limited to organic food but is general.

101 Prior research has discussed this issue primarily based on inferences from quantitative studies, 102 typically using choice experiments or other conjoint approaches. Hence, there is a lack of research 103 that investigates origin preferences and their underlying reasons in a direct way and in more detail.

104 On this background, it is the objective of this study to investigate if and why consumers prefer 105 imported organic food products from some countries compared to others, in particular countries at 106 the same level of economic development, and which role geographical distance plays in this connection. By doing so, this study fills a gap in current knowledge about consumer preferences for organic food and $\mathrm{COO}$ in general, and in particular regarding the role of geographical distance in 109 this connection.

110 To reduce the risk of demand effects and response biases, we approach this topic by means of two 111 different open interview formats, using qualitative, individual and group interviews in different 112 geographical locations. We collect information about consumer attention towards the origin of 113 organic food products and about their preferences for imported organic food products from different 114 origins, and reasons for these preferences, in the actual buying situation as well as in a situation that 115 is similar to everyday conversations with acquaintances. Specifically, we aim to answer the 116 following research questions:

\footnotetext{
${ }^{1}$ Take Denmark as example, due to its unusually detailed national statistics on the matter. Germany is Denmark's most important export market for organic products, accounting for 39 per cent of total organic exports in 2016, followed by Sweden (19 per cent), China (12 per cent) and France (8 per cent) (Danmarks Statistik, 2017). The most important origin countries for imported organic products to Denmark are Germany (22 per cent), the Netherlands (19 per cent) and Italy (16 per cent) (Danmarks Statistik, 2017).
} 
117 (1) Which role does the COO play for organic food consumers when evaluating organic food 118 products, and if any, why?

119 (2) Do organic consumers prefer certain CsOO for imported organic food products over others, and 120 if so, why?

121 (2a) More specifically, do preferences for certain $\mathrm{CsOO}$ for imported organic food products depend 122 on the geographical distance to the $\mathrm{COO}$, and if so, why?

123 Germany was chosen as the location for the study because (a) it is the second largest market for 124 organic food in the world, (b) it is surrounded by countries that are similar in cultural and economic characteristics and are major exporters of organic food products to Germany, and (c) it is large enough to offer locations with a substantially different geographical distance to neighbouring countries, depending on citizens' residence.

\section{Material and methods}

The study applied a qualitative, multi-method approach, employing two different methods to offset counteracting biases and triangulate findings (Greene, Caracelli, \& Graham, 1989): short and structured personal interviews in stores, intercepting consumers while they were making food product choices, and semi-structured focus group interviews, which were longer and provided opportunities to delve more in depth into motives and preferences for $\mathrm{CsOO}$. Hence, the in-store interviews provided insights into consumer attention to $\mathrm{COO}$ while shopping organic food, their salient COO preferences and accessible reasons for these preferences, while the focus groups provided more depth to understanding of how consumers make sense out of COO information and what it means to them when buying organic food.

Besides supplementing each other, investigator and methodological triangulation is an important advantage of employing two different methods (Denzin, 2009). To obtain investigator triangulation, two researchers gathered the data - by means of in-store interviews and focus groups - and five researchers interpreted them. Two researchers coded data separately and the whole group discussed codes and categories in order to offset possible researcher biases. Methodological triangulation is achieved by investigating the same phenomena - consumer perceptions and evaluations of country-of-origin for organic food products - by two different methods, complementing each other in width and depth (Lincoln \& Guba, 1986). For the in-store interviewers, consumers were intercepted at the point where they were actually making the type of 
decisions in focus, which makes questions less hypothetical and answers more valid. The focus group interviews were designed to emulate everyday conversations with friends and colleagues, where people share beliefs and opinions on topics brought to the table and where they can explain and justify their opinions and actions (Kitzinger, 1994).

151 Data were collected in three German cities: Hamburg (north, $160 \mathrm{~km}$ from Denmark), Munich 152 (south, $115 \mathrm{~km}$ from Austria) and Münster (west, $70 \mathrm{~km}$ from The Netherlands). In our data 153 collection, we aimed to capture consumer perception of imported organic food products in general, 154 rather than product specific perceptions. Therefore, we made sure to cover the biggest, broad organic product categories, which can be both domestically produced and imported: vegetables, dairy products and meat. In this way, we covered most of everyday organic product shopping while diminishing a possible biasing influence from specific products with a strong origin image (like Mozzarella cheese and Italy or Feta cheese and Greece). The three product categories are produced in all of Germany's neighbouring countries, which means that many different countries could in principle be the origin of import to Germany within these categories. Because data were collected in several different places (different cities, different shops, and two focus groups in each city) and hours (different days and time of day), the study design also allowed within-method data triangulation, which further increases the reliability of the findings. Results from the in-store interviews are presented first, followed by results from the focus groups, and finally the findings are synthesized.

\section{Study 1: In-store interviews}

\subsection{Procedure}

168 The in-store interviews took place at Rewe (the second largest general food retailer in Germany, cf.

169 Tagesspiegel, 2015) and denn's Biomarkt (the largest specialty retailer for organic products, cf.

170 Pabst, 2014). This choice of retailers made it possible to hold store types constant across cities. In

171 Germany, specialty stores have a high market share of organic food (about 33\%, cf. Moewius,

172 Röhrig, \& Schaack, 2018), and since they might appeal to a different type of organic consumers 173 than conventional supermarkets, we found it important to have both represented. Organic 174 consumers were intercepted at the point of purchase in a natural buying situation. At Rewe, 175 consumers were approached after they had made their choice and put an organic product in their 176 shopping basket. As denn's Biomarkt only sells organic products, this allowed us to approach 177 consumers even before they had added products to their shopping basket. 
The interviewers followed a structured interview guide with six questions (besides sociodemographics) designed for each interview to last approximately five minutes. The interviewer briefly introduced the study without revealing the actual aim to avoid a potential bias through unintended triggering of associations with the topic. The six questions were about (1) how frequently the participant bought organic food (scale from 0 (never) to 5 (always)), (2) the importance of COO (yes/no/sometimes) and why, (3) the attention to COO information on products (yes/no) and (4) attitude towards $\mathrm{CsOO}$ (which products, why/why not), (5) importance of COO for other products and (6) preference for $\mathrm{COO}$ of imported products and why. Except for questions 5 and 6, all questions were related to the product category (dairy, vegetables or meat) in the section of the shop where the interview took place. Interviews were conducted on weekdays and during the same time periods (10:00 to 14:00 and 16:00 to 19:00) in all shops. Interviews were audio recorded with consent and transcribed verbatim.

For the open-ended questions (such as reasons for buying from a particular $\mathrm{COO}$ or avoiding others), the verbatim text was first carefully read and re-read and categories of main response types were developed. To capture the viewpoints of the participants as precisely as possible, these were not defined a priori; instead an inductive approach to content analysis was employed (Krippendorff, 2004). The categorisation was discussed between researchers and a coding manual was created with codes such as purchase of imported organic food, attention to COO, importance of $\mathrm{COO}$, preferences for $\mathrm{CsOO}$, reasons for COO-preferences and avoidance. The codes were used in a content analysis guided by this study's research questions. For selected research questions (such as preferences for $\mathrm{CsOO}$ ), a summative approach to content analysis was applied (H.-F. Hsieh \& Shannon, 2005). This approach differs from "conventional" content analysis, which is also employed, but is useful when a large number of interviews are analysed. The "quantification is an attempt not to infer meaning but, rather, to explore usage" (H.-F. Hsieh \& Shannon, 2005, p. 1283). The summative approach involves counting specific keywords, but also interpreting the underlying context, as is the aim regarding $\mathrm{CsOO}$ preferences in this study. When using a summative approach with a large sample size, it can be meaningful to conduct simple statistical tests, such as chi-square tests of relationships between counts.

A total of 255 organic consumers (68\% female, overall mean age 45 (SD 14)) were interviewed during six days in March 2016 (93 in Hamburg, 81 in Munich and 81 in Münster). See Table 1 for socio-demographic characteristics of the sample. Participants were considered regular organic consumers if they claimed to buy organic always (scored 5 on the scale for organic buying 
frequency) or quite often (scored 4). They were considered occasional organic consumers if they

211 bought organic food from rarely to about half of the time (scoring from 1 to 3 on the scale for

212 organic buying frequency). Participants that never buy organic food were dismissed and not

213 interviewed any further.

[Insert Table 1 around here]

\subsection{Results}

\subsubsection{Importance of $\mathrm{COO}$}

217 The majority of in-store participants (76\%) stated that the $\mathrm{COO}$ of an organic product mattered to them. Only $16 \%$ indicated that the origin was unimportant when purchasing organic foods and for $8 \%$ of the participants, it mattered only sometimes or in specific situations (see Table 2).

Although COO seems to matter most in Munich, less in Münster, and least in Hamburg, the difference is not statistically significant $(p=.29)$. The importance of COO varied with organic purchase frequency: While $84 \%$ of regular organic consumers considered the product's COO important, only $38 \%$ of occasional organic consumers did so $\left(\chi^{2}(8 \mathrm{df}\right.$. $\left.)=28.25, p<.001\right)$. Further, COO was more important for shoppers at denn's than at Rewe $\left(\chi^{2}(2 \mathrm{df})=13.91,. p<.001\right)$.

The reasons why a product's $\mathrm{COO}$ was considered important differed only marginally between the three cities. Overall, a domestic country bias was pronounced: Most of the participants indicating that $\mathrm{COO}$ matters spontaneously mentioned a preference for domestic products. Of these, $75 \%$ indicated that they particularly preferred local products. Some participants elaborated on their preference by describing some sort of radius or ranking with local products being most preferred,

231 followed by domestic products and imported alternatives in some cases being acceptable as the last 232 resort. Participants also described a goal conflict when they had to decide between a conventional 233 local product and an imported organic product. Only very few participants spontaneously 234 mentioned that they actively avoided products from certain origins.

\subsubsection{Attention to $\mathrm{COO}$}

236 When asked about their attention to COO information when buying organic food, 37\% of in-store 237 participants said they always paid attention to the COO, while $27 \%$ did so sometimes, $11 \%$ inferred 238 the COO from the product and 23\% did not consider the COO (see Table 2). Half of the regular organic consumers stated that they always pay attention to the origin, while only $15 \%$ of the 
occasional organic consumers did so $\left(\chi^{2}(12 \mathrm{df})=37.76,. p<.001\right)$. Attention to COO varied

241 between cities: While 53\% of consumers in Münster stated to always pay attention to the COO, 242 only $28 \%$ did so in Hamburg and 34\% in Munich $\left(\chi^{2}(6 \mathrm{df}\right.$. $\left.)=14.67, p<.01\right)$. Finally, 39\% of 243 denn's customers always paid attention to COO against $33 \%$ at Rewe $\left(\chi^{2}(3 \mathrm{df}\right.$.) $=13.31, p<.05)$.

244 Consumers' knowledge about the COO of (a) product(s) they had just put in their shopping basket 245 was also explored. Only $40 \%$ of the consumers, who indicated to at least sometimes pay attention to 246 the COO, could state the correct origin of a product just chosen, whereas $41 \%$ did not know the 247 COO. The remaining 19\% correctly stated the COO, for instance by reasoning that at that particular 248 time of year, asparagus normally comes from Spain.

249 When asked why they did not pay attention to the COO, the most common reason, given by $34 \%$ of 250 the participants who never or only sometimes pay attention to the product's origin, was that it is 251 sufficient to know that the product is organic. One participant explained:

252 'Now, when it says 'organic' on the label, then I am just too naïve ... then I think this product is 253 organic, even if it is from Poland or the Netherlands or wherever ... I simply trust this labelling." 254 (Female, 32, denn's, Hamburg)

255 Hence, organic labelling and certification often override the importance of COO for these 256 consumers.

257 Other reasons for not considering $\mathrm{COO}$ were that taste (based on previous experience) or the 258 packaging were more important (e.g., plastic wrapping was considered unfit for organic products). 259 Also, some mentioned that when shopping in an organic shop, the shop itself functioned as a cue to 260 quality, and, hence, that less attention to the COO was needed.

\subsubsection{Preferences for COO of imported organic food products}

262 The domestic country bias aside, when in-store participants were asked about their preferences for imported versions of a specific organic food product (defined by the aisle, where the consumer was approached for interview), they expressed a strong preference for specific and geographically close countries of origin. Austria was the most preferred foreign COO in Munich and the Netherlands the most preferred in Münster. In Hamburg, products from Denmark were preferred substantially more than in Münster and Munich. In Münster and Munich, Denmark was seldom or not mentioned at all as alternative COO. In Hamburg, participants preferred Dutch or French over Danish products, but the difference was not significant. Hence, in Munich and Münster, the geographically closest COO 
was clearly preferred (Austria and The Netherlands, respectively), and in Hamburg, closest to Denmark, there was a considerably stronger preference for Danish products than in the other two cities. Figure 1 shows the percentage of participants in the three cities mentioning a specific COO as preferred for imported organic products.

\section{[Insert Figure 1 around here]}

When asked to explain their preferences for a specific foreign $\mathrm{COO}$ of organic products, reference was made to general country associations based on familiarity and experience as well as the perceived ecological image of a country. When participants in Hamburg considered Denmark as a geographically close $\mathrm{COO}$, more than half of them perceived Denmark as an equally fine alternative to Germany or other preferred countries. Very few of them $(<10 \%)$ did not consider buying Danish products out of animosity or because they did not regard Denmark as geographically close enough. Otherwise, no negative associations were mentioned; rather participants exhibited a generally high trust in Denmark as a country:

\section{"Of course ... Denmark would be easy because we somehow have a special relationship to} Scandinavia here. One would not put something bad past Scandinavians ... in comparison to any Southern European countries, especially regarding fruit and vegetables. Sure, maybe I have a more positive sensation [regarding Denmark].” (Male, 36, Rewe, Hamburg)

However, although most participants did not reject Denmark as COO per se, they had never thought about buying Danish products, since they were not familiar with the country as a producer of these products. This was especially evident for vegetables. Many participants stated that they could not imagine Denmark having the adequate climate to grow these products. They felt unable to evaluate Denmark as COO, because they were uncertain about the country's organic legislation and had too little knowledge about Danish products:

"I spontaneously just did not think about it (...) But ok, that's true. Denmark is closer for us here in the North. That's right. But I don't know how the status is in Denmark regarding organic products. That's why ... I simply never heard anything about it.” (Female, 47, denn's, Hamburg)

Participants in Munich (and to a lesser extent in Münster and Hamburg) had rich associations to Austria based on direct experience, such as holidays or having studied there. In addition, many of the participants in Munich had considerable knowledge of Austria's culture, history, language, traditions and food culture. Participants also associated Austria with a positive environmental image. 
301 Participants in Münster had richer associations with the Netherlands than participants in the other two cities. Many of these participants perceived the Netherlands as a close neighbour, which was reflected in their associations regarding culture and traditions. However, some participants associated the Netherlands with a mixed environmental image based on previous food safety issues: "Well, I think The Netherlands has made progress, since earlier there were issues both with tomatoes, but also with cheese." (Male, 57, denn's, Münster)

\subsubsection{Reasons for COO preferences}

308 The in-store participants' ten main reasons for preferring geographically close CsOO are shown in 309 Table 2. Overall, and across the three cities, the main reason (mentioned by $58-88 \%$ ) was short 310 haulage distance, which was also the major reason for preferring both domestic and local products. 311 Several reasons were given for emphasizing short haulage distance. First, most participants 312 considered geographically close origins more sustainable due to less environmental pollution from 313 transportation and storage. This environmental concern was linked to the basic motivation for 314 buying organic products, as expressed by one participant:

315 'I think it's tricky when it says organic on the label and it's from Peru, and I could have bought the same product from our local suppliers. In that case, organic is just an alibi for me, considering the $317 \mathrm{CO}_{2}$ emissions ... all the things that come together then ... no, then I'd rather buy regional." (Male, 318 40, denn's, Munich)

319 Second, for the special case of meat, some participants preferred geographically close origins to 320 keep livestock from being transported over longer distances. Third, for a few participants, shorter 321 haulage distance, and with that reduced storage time, was associated with fresher and to some 322 degree healthier products. Thus, a reason to buy from geographically close COOs was to avoid 323 preserving agents or additives, as expressed by one participant:

324 "The [process of] import ruins the products, so they have to add additives." (Female, 37, denn's, 325 Hamburg)

326 Trust in standards was the second-most mentioned reason in Hamburg and Munich and the fourth327 most mentioned reason in Münster. As one participant put it:

328 "Well, I say that organic in Spain is the same, or almost the same, as organic in Germany. The 329 standards must comply. But of course, there is no way I can check it..." (Male, 47, denn's, 330 Münster) 
331 The third-most mentioned reason for preferring a specific COO was country image, which in the 332 case of organic food primarily means a country's 'green image'. This reason was mentioned by $33321 \%$ in Münster, $8 \%$ in Munich, but only 3\% in Hamburg.

\section{$334 \quad 3.3$ Discussion}

335 In all three cities, the majority of the interviewed consumers claimed to consider whether organic 336 products are domestically produced or imported and that the COO is important. The participants' statements suggest more attention to the $\mathrm{COO}$ when buying organic food than found in past research (Liefeld, 2004). Regular organic consumers and consumers shopping in an organic store (denn's) find the COO more important and think more about it than occasional organic consumers and consumers shopping in a regular supermarket (Rewe). However, less than half of the participants were actually aware of the origin of the product they had just chosen, despite having stated that they paid attention to it. These findings suggest that consumers might pay less attention to $\mathrm{COO}$ than they claim, perhaps because of a social desirability bias in their answers. The study also confirmed prior research finding that (in this case German) organic consumers prefer geographically close origins for imported organic food products (Hempel \& Hamm, 2016a, 2016b). The by far most frequent reason given for preferring a geographically close COO, in all three cities, was the haulage distance, primarily due to the negative environmental and animal welfare consequences of long transport distances. This suggests that the $\mathrm{COO}$ of organic products is of particular relevance to organic consumers due to their wish to act in a pro-environmental way, including buying organic food (Thøgersen, 2011). This might also be the reason why regular organic consumers and shoppers at denn's pay significantly more attention to COO than occasional organic consumers and shoppers at Rewe. However, as illustrated by the fact that (marginally) more participants in Hamburg preferred France to Denmark as COO, the positive evaluation of a COO is not only based on transport distances. Other factors, such as trust in standards and country image, 355 play a role as well.

356 Trust in a foreign country's organic standards was the second most important factor, which 357 confirms previous research finding trust to be an important factor (e.g., Nuttavuthisit \& Thøgersen, 358 2017, 2018; Padel \& Foster, 2005). This underlines the importance of trustworthy certification 359 schemes for the development of an organic market and not least for international trade in organic 360 products. 
361 In Münster, the Netherlands was found to be a strongly preferred COO, even though consumers

362 here also expressed negative associations to the country. This suggests that the positive perceptions

363 and associations, such as short haulage distances, more than compensate for the negative

364 associations. It is also possible that the very high familiarity with the Netherlands in Münster, due

365 to the geographical proximity, means that negative publicity incidences only marginally influence

366 consumers' evaluation of products from the country. This latter reasoning is supported by the fact

367 that Dutch products were avoided to a lesser degree in geographically nearer Münster and Hamburg 368 than in Munich.

\section{Study 2: Focus groups}

\section{$370 \quad 4.1$ Procedure}

371 Two focus groups (5-7 participants in each) were conducted in each of the three cities in March

372 2016. Participants were recruited by distributing an illustrative flyer addressing organic consumers

373 through various media channels, supplemented by snowball sampling (Bryman \& Bell, 2015).

374 Potential participants were screened for being at least partly responsible for grocery shopping in

375 their household and for at least sometimes buying organic food (at least one organic food product

376 during the past two weeks).

377 With one exception, there were at least two representatives of each gender in each group. Each 378 group consisted of at least one participant under 30 and one over 50 years. Overall, 63\% females 379 participated and the mean age was 36 years. $45 \%$ of the participants were students, $47 \%$ employed 380 and the rest were retired or unemployed (see Table 3). All in all, the focus groups represented a 381 broad sample of German consumers.

383 To guide the focus group discussions, we developed a semi-structured interview guide consisting of 384 open-ended questions about three topics of interest, allowing for a non-directive open conversation 385 (Kitzinger, 1994). Various techniques, such as participants writing associations on paper or ranking 386 countries (using flags) before discussing questions, were employed to uncover participants' less 387 accessible perceptions, associations and attitudes (Malhotra, Birks, \& Wills, 2012) regarding CsOO. 388 All focus groups were facilitated by a moderator with the support of an assistant. The focus groups 
lasted on average 1 hour and 48 minutes. Participants received a EUR 10 gift card for their time and effort.

391 The first topic was country associations (Usunier \& Cestre, 2007); participants were asked to write 392 down their associations to three selected countries (Austria, the Netherlands and Denmark) on a 393 piece of paper and to briefly explain their associations. Afterwards, participants were asked to rate 394 the three countries on a scale from 0 (least favoured European country) to 10 (most favoured 395 European country) and explain their rating.

396 The second topic focused specifically on the combined effect of organic food and COO.

397 Participants were asked about their attention to COO of organic products and how important they 398 thought the COO was. Also, participants were asked to explain their preferences for CsOO. Next, 399 participants were given a list of 10 European countries and were asked to indicate which country on 400 the list they trusted the most and least as an organic producer.

401 Audio recordings of the focus groups were transcribed verbatim by one of the two research 402 assistants managing the interviews and checked by the other research assistant to ensure 403 consistency. Content analysis was performed using Nvivo11, which is able to take both the content 404 and the context of the data into account (Krippendorff, 2004). The verbatim text was read and re405 read and then an initial open coding was carried out taking an inductive approach. Next, categories 406 were developed based on the research questions of the study. The main categories were: The role of $407 \mathrm{COO}$ of organic food products, preferences for $\mathrm{CsOO}$, reasons for preferring $\mathrm{CsOO}$ and positive 408 and negative associations to various countries, including the Netherlands, Austria and Denmark.

\section{$411 \quad 4.2 .1$ Country associations and evaluations}

412 Most of the participants in all three cities had rich associations to Austria. Participants in both 413 Munich and Münster related Austria to a great variety of experiences based on frequent holidays 414 and personal relations, and they demonstrated a great understanding of Austria's culture and 415 traditions. They associated Austria with a diverse countryside and outdoor activities. Participants in 416 Hamburg had slightly fewer associations to Austria, but some participants nevertheless perceived 417 Austria as a neighbour: 
"The first thing that came to mind was that people from Austria are our neighbours. This is why I wrote down neighbour ... as country, people ... as everything.” (Female, 30, FG1, Hamburg)

Some participants expressed that Austria has a positive environmental image related to organic food production, support for local farmers and a progressive social system:

"It is an extremely social country and also extremely green. So they are leaders when it comes to organic" (Male, 31, FG1 Munich)

Like Austria, participants had rich associations to the Netherlands. In Münster, many participants perceived the Netherlands as a close neighbour:

"Generally, I can say that Holland or the Netherlands is a country where I go at least once or twice a year on a short vacation ... It is easy to spend the day at the sea, because it is so close." (Female, 25, FG1, Münster)

This proximity was also reflected in participants' associations regarding Dutch culture and traditions, including associations to traditional meals and food products (especially cheese and fish), as well as personal connections to the Netherlands. Slightly less pronounced associations to the Netherlands were found in Hamburg and Munich, but most participants associated the Netherlands with Amsterdam and a liberal culture. Especially in Munich and Hamburg, the Netherlands was associated with a mixed environmental image; some participants referred to sustainability, reflected in water usage and solar energy, whereas others mentioned mainly energy-demanding greenhouses and genetically modified vegetables:

"I connect Holland mostly with a lot of greenhouses where they grow vegetables and cabbage. Tomatoes from the Netherlands I definitely avoid." (Male, 32, FG2, Munich)

Consistent with what was found in the in-store interviews, the majority of participants across the three target cities had very few associations to Denmark. Those that were expressed especially related to political events, culture or nature. Participants in Hamburg associated Denmark with negative publicity about the refugee crisis and right-wing movements. These negative associations were less prominent in Munich and Münster. Although many participants in Hamburg had direct experience with Denmark during holidays, they did not seem very familiar with the country: "Somehow I associate Denmark with the colour white. I think that the beaches and landscape are so sparse there. Somehow such a white memory. I don't know why." (Female, 55, FG2, Hamburg) 
447 Participants in Munich had less direct experience with Denmark. Beyond basic associations to

448 Copenhagen, some perceived Denmark to be sustainable and progressive, while others only

449 associated Denmark with being a transit country when traveling to other Scandinavian countries.

450 Similar results were found in Münster, however with more participants associating Denmark with

451 holidays based on childhood memories. Denmark tended not to be associated with food in any of

452 the three cities, except for Munich where some participants associated Denmark with organic food.

453 When rating the countries in terms of favourability, participants stated the main reasons for their 454 rating and whether it added positively or negatively to their overall evaluation of the country. An 455 overview over the rating and main reasons is presented in Table 4.

Austria was rated differently by participants in the three cities. Whereas many participants in Hamburg were rather neutral towards Austria, the majority of participants in Munich and Münster rated Austria very favourably. In Hamburg, a considerable number of participants seemed to base their evaluations primarily on political events and perceived, right-wing tendencies in the Austrian society. These views were balanced by a food culture and countryside that were positively

463 evaluated. In Munich, most participants had a variety of positive associations to Austria.

464 The Netherlands was rated positively in all three cities. In Hamburg, most participants especially 465 appreciated the diverse culture and open-minded society. In Munich, many participants evaluated 466 the Netherlands positively based on their perception of a progressive and multi-cultural society. 467 Several participants also took the Netherlands' environmental image into account, which led to both 468 positive and negative evaluations. Similar results were found in Münster where participants had 469 considerable experience with the Netherlands and overall ranked the country very favourably.

470 The majority of participants across all three cities evaluated Denmark positively based on 471 favourable associations from direct and indirect experience. Yet, a considerable number of 472 participants also indicated that they are indifferent about Denmark due to a lack of experience and 473 interest in the country.

\subsubsection{COO preferences for imported organic food products}

475 When exploring the combined effect of organic food and COO, participants were asked to think 476 about a typical grocery shopping trip and imagine they were choosing an organic product. The 
majority of participants across the three cities reported that they actively paid attention to the COO of organic products. Especially in Munich, participants explained how they noticed a strong presence of Austrian products in supermarkets, indicated by the Austrian flag. Yet, some participants also mentioned that they often did not pay attention to the COO. Further, across all three cities, a majority of the participants indicated that the organic label is more important: "I know that I feel a little bit on the safe side if I buy organic. I think that at least it's organic, so it's not too bad no matter if it comes from here or there." (Female, 23, FG1, Münster)

Other participants emphasized different organic producer organisations, such as Demeter or Bioland. These participants were well-informed about the standards set by these producer organisation labels and perceived them as more trustworthy and rigorous than the European organic label. Participants choosing organic products based on these labels tended to disregard the COO. Participants generally preferred local or at least domestic food products. Especially in Hamburg and Munich, most participants stated that they mainly preferred food products from their local area:

"I know that it refers to how products are grown and that they are not fertilized, but for me, when I buy organic I also want it to come from my immediate surroundings.” (Female, 25, FG1, Hamburg) Participants in Hamburg and Munich also had strong opinions on what 'local' means: It only includes the local area around their home and inside the national borders. In contrast, many participants in Münster had a somewhat broader understanding. Some regarded the Netherlands as a suitable alternative to local or domestic products:

"I buy vegetables and fresh produce only from nearby, this means Germany or Holland mostly ..." (Male, 25, FG2, Münster)

Participants from all three cities associated local products with organic. A few preferred local conventional products over imported organic ones:

"Well, I would rather, let's say if ... there is organic butter from Denmark and butter from Traunstein without an organic label, I would buy the butter from Traunstein." (Female, 26, FG 2, Munich)

Some participants argued that long transport distances did not correspond with their motivation for buying organic while others preferred local products either because they wanted to support local farmers and their region or because they distrusted imported organic food. 
506 When asked to explain their preferences for $\mathrm{COO}$, the most prominent reason was the environmental impact of transport. Some participants in Münster indicated that they preferred

508 buying imported organic products from neighbouring countries: "At the supermarket, I actually buy only from Holland or Belgium, because I believe it's stupid to have trucks drive for one thousand kilometres, if the same product is grown in your neighbouring country.” (Male, 25, FG2, Münster)

512 Based on similar reasoning, some participants refrained from buying organic products from 513 countries where they perceived the costs of growing organic disproportionally high.

514 Across the three cities, many participants said that they refrained from buying imported organic products that could be produced domestically. This was particularly discussed regarding milk and vegetables. In the case of vegetables, a considerable number of participants strongly emphasized the importance of seasonality. They insisted on buying some vegetables, such as asparagus, only when they were in season:

"We have so much asparagus in our immediate area surrounding Munich ... I think that one doesn't need to get asparagus from Greece six weeks before its available here.” (Male, 32, FG2, 521 Munich)

522 Yet, some participants also admitted that they were tempted by organic products from outside Germany and that they bought them despite their preference for local or domestic products. Finally, the environmental image of a country also played a role for participants' preferences for foreign CsOO. Among a selection of 10 European countries, most participants picked Austria and Switzerland as the most trustworthy producers of organic food. In all three cities, these two countries were described as reliable, progressive and trustworthy and associated with a green image. Many participants also perceived them as similar to Germany, reinforcing their trust in these two 530 European countries, due to, among other things, perceived inferior quality and scandals connected 531 with high pesticide usage, which fed into a negative ecological image. Although some participants had similar associations with vegetables coming from the Netherlands, more participants believed

533 the opposite. The Netherlands seem to have recovered from a negative environmental image, but 534 some still perceived it as untrustworthy due to heavy use of pesticides. In comparison, Denmark 535 was rarely associated with any environmental image at all. Some participants perceived Denmark 
536 negatively as an organic producer, others as progressive and sustainable, in both cases without 537 specific reasons.

\section{$538 \quad 4.3$ Discussion}

539 Consistent with prior research finding that COO information can trigger country stereotypes (Herz 540 \& Diamantopoulos, 2012; Pharr, 2005), participants across all three cities shared a variety of 541 stereotypical beliefs about and associations with Austria, the Netherlands and Denmark. The richness of these associations was strongly influenced by participants' experience with the country (cf. Verlegh \& Steenkamp, 1999). Particularly, many participants were very familiar with Austria and the Netherlands, which was clearly reflected in the richness of their associations to these two countries. In contrast, most participants had few and weak associations to Denmark. Although several participants had personal experience with Denmark, few participants felt familiar with the country. This can partly be explained by Denmark not being an obvious holiday destination for participants and perhaps that Denmark is perceived as culturally more different from Germany than Austria and the Netherlands.

550 Finally, several participants mentioned environmental associations to foreign countries. This could 551 be due to them being engaged organic consumers, buying organic foods regularly. Not all of them 552 did that, though - due to the screening, they could buy organic food products as rarely as once 553 every two weeks. However, in a conversation with other organic food consumers, some of which 554 are very dedicated, it seems likely that environmental aspects become more accessible, also when 555 thinking about specific countries. The environmental associations also seem to impact the 556 trustworthiness of specific countries as $\mathrm{COO}$ of imported organic products. Notably, Austria was 557 rated as trustworthy, the Netherlands got a more mixed evaluation, and Denmark was not really 558 associated with an environmental image.

559 Although it is often reported that consumers' knowledge of a product's COO is limited (Liefeld, 560 2004), the focus groups revealed a high involvement with the COO of organic products.

561 Participants considered it important for a number of reasons and consequently took the COO into 562 account when shopping. Especially, a significant number of participants stated that they consider 563 the negative environmental effects of transport and production when buying organic food. This is 564 consistent with the proposition that consumers buy organic products not only for selfish reasons, but 565 at least partly for ethical reasons (cf. Thøgersen, 2011). 
566 Consistent with Study 1 and previous research (e.g., Dransfield et al., 2005; Kledal, El-Naggar, 567 Sirieix, \& Auersalmi, 2011; Sirieix, Kledal, \& Sulitang, 2011), Study 2 revealed strong preferences 568 for local (from the region) and domestic organic products. Across all three cities, participants 569 preferred local or at least domestic products, but the strength of these preferences varied. Local 570 preferences for organic food were mostly grounded in environmental aspects of transport while 571 some also mentioned willingness to support the local economy. Also, it seems that local and 572 domestic origins make more of a difference for product evaluations than the COO of imported 573 organic products. Still, it is reasonable to conclude that participants' preferences for certain CsOO 574 were - at least partly - rooted in them valuing short transport distances and sustainable production 575 methods.

\section{General discussion}

577 Organic consumers' preferences for imported organic food products from different origins were 578 investigated by means of two different qualitative methods employing investigator, methodological 579 and within-method triangulation to increase the robustness and reliability of our results. Both 580 studies focused on consumers' perceived importance of and attention to COO, their specific COO 581 preferences and their underlying reasons. Participants were sampled from three different geographical locations (north, west and south in Germany).

583 The two studies revealed that the COO of organic food products is important for most of the 584 participating consumers. A few of the participants expressed that they do not care much about the $585 \mathrm{COO}$ as long as the product is organic. However, most of them claimed that they consider both $586 \mathrm{COO}$ and organic when they assess food quality and safety. Among other things, a product's COO 587 is used to make inferences about the trustworthiness of an organic label, thereby reducing the 588 perceived risk when buying organic products. Thus, many consumers seem to use the COO cue 589 together with the organic label, rather than independently.

590 Further, the studies confirm prior research finding that organic consumers in Germany have strong 591 preferences for organic food products from geographically close compared to more distant origins, 592 and they extend this finding to $\mathrm{CsOO}$. The cross-regional approach revealed a clear preference for 593 Austrian, respectively Dutch, products in the geographically nearby cities of Munich, respectively 594 Münster. It also revealed a considerably stronger preference for products from Denmark in 595 Hamburg than in the other two cities. Prior COO research has inferred that geographical distance is 
one of the antecedents of COO evaluations (M.-H. Hsieh, 2004; Rosenbloom \& Haefner, 2009). However, this inference has rarely been tested empirically. Also, contrary to what is often assumed in this line of research, familiarity as such was not consumers' main reason for preferring nearer

599 CsOO. Instead, the main reason was shorter transport distance, which seem to be primarily rooted 600 in environmental concern (cf. also Lazzarini et al., 2017). Hence, preferences for foreign CsOO for 601 organic food products appear to be primarily rooted in concerns about the negative environmental 602 effects of transport, followed by trust in standards, familiarity and general country image.

603 However, it is challenging for consumers to assess food products' environmental friendliness. For 604 example, whereas the environmental impact of food transportation depends more on the 605 transportation mode than the distance, consumers generally pay much more attention to the latter 606 than the former (Tobler et al., 2011).

607 The two studies also confirmed past research finding a strong preference for local and domestic 608 organic products (e.g., Dransfield et al., 2005; Xie et al., 2016). This preference is also attributed to 609 the short haulage distance, but also reflects support of local economy and more generally a 610 domestic country bias. Most of the participating organic consumers were aware of the trade-off they 611 sometimes have to make between imported organic food products and domestic conventional ones, 612 which underlines the complexity of decision-making regarding organic food products (Padel \& 613 Foster, 2005).

614 General country images appear to be another important reason for COO preferences. The focus 615 group discussions revealed that country associations are based on stereotypical beliefs, indirect and 616 direct experience, media coverage, etc., and that they ultimately influence consumers' evaluation of 617 products from the country in question. In the case of organic food, the general country image and 618 trust in organic standards seem to merge into an environmental image, which plays a particularly 619 important role in the evaluation of foreign $\mathrm{CsOO}$ in the case of organic products, but also in the overall evaluation of a country. Some countries have a better environmental image than others, but no major differences in the perception of a country's environmental image were found based on

622 geographical proximity. For example, Austria seems to have a positive environmental image in all 623 three cities, while Denmark seems to be perceived rather neutral in this regard and the Netherlands 624 seems to slowly recover from a negative environmental image. 
626 Several limitations should be kept in mind when interpreting the results of this study. First, due to

627 its qualitative nature, causal relationships underlying $\mathrm{COO}$ evaluations, such as the relationship

628 between distance and preference for a country as COO, cannot be determined. Hence, future

629 research should determine the causality between the variables studied, if possible by means of

630 experiments. Because familiarity and experience with a specific country are linked to geographical

631 distance, it is a limitation that consumers did not evaluate foreign countries with the same level of

632 familiarity. Hence, future studies should study familiarity and geographical distance in a setup that

633 enables disentangling the influence of these two aspects. Future research should also measure the

634 causal impact of other antecedents (e.g., environmental image, environmental concerns) and

635 moderators of $\mathrm{COO}$ evaluations (e.g., type of organic label, certification agency, characteristics of

636 the importing country).

637 Second, this study only covered one country and did not cover all its major regions, only the north,

638 south and west. In the future, a similar study might be conducted in other countries and also in other

639 regions of Germany, especially the eastern part where preferences for COOs has previously been

640 found to differ from the west of Germany (Hempel \& Hamm, 2016b). Also, the focus was on CsOO

641 with a short distance to Germany (i.e., neighbouring countries). Future studies should address the

642 influence of distance for $\mathrm{CsOO}$ by including $\mathrm{CsOO}$ with different distances to further improve our

643 understanding of the importance of distance.

644 Another limitation is that especially the focus group participants are likely to be more involved in 645 organic food than average organic consumers, since they volunteered to participate in a focus group 646 about organic food. There was also quite a high proportion of students in our focus group samples, 647 which might have biased results in the direction of small, young, well-educated households. Finally, 648 the findings are based on participants' self-reported behaviour, which may give a biased 649 representation of their actual behaviour. For example, less than half of the participants in the in650 store interviews were aware of the origin of products in their shopping cart even though they stated 651 they paid attention to it. Hence, it is likely that participants do not evaluate the COO of organic 652 products as thoroughly in a natural buying situation as they report (and possibly think) they do. 653 Also, despite all the attempts to increase reliability and validity of the collected data, overreporting 654 due to social desirability bias cannot be ruled out completely, for example, participants (consciously 655 or unconsciously) guessing what the interviewer wants to hear or just wanting to impress the 
interviewer with an image of being well-informed and responsible. Hence, the size of such biases should be investigated in future studies.

\subsection{Conclusions and implications}

660 Based on the studies reported here, it can be concluded that the participating consumers prefer that 661 imported organic products come from nearby $\mathrm{CsOO}$. The reasons for this preference are primarily 662 perceived negative environmental impact of transport, followed by trust in standards and the image 663 of the exporting country. It is an important contribution of this study that it has generated evidence 664 to support prior inferences about the importance of geographical distance for COO preferences as 665 well as insight into why geographical distance is important for consumer preferences for various 666 origins of organic food.

667 The deeper understanding of the reasons for COO preferences produced by this research is not only 668 theoretically, but also practically relevant, especially for exporters of organic food. Exporting countries should especially focus on market entry and expansion to geographically close regions of bordering countries. Organic consumers' environmental concern also influences their evaluation of

671 haulage distance, which can lead to a stronger preference for a nearby COO. As a result, it is 672 suggested that exporters of organic food use the uncovered reasons for COO preferences to better 673 understand the markets they are dealing with. Hence, consumer segmentation based not only on 674 preferences but also on geographical location is relevant when preparing an export strategy.

675 The findings also suggest that organic exporters benefit from a positive environmental image of 676 their home country in the target market. Obviously, it is difficult for individual organic exporters to 677 influence the general country image, which consists of associations to, for example, politics and 678 culture and stereotypical beliefs based on experience with a country. Therefore, collaboration - for 679 example in national organic producer organizations - seems vital to strategically build and 680 communicate a positive country image.

681 Overall, this study's findings expand the scarce research on COO effects in the context of imported 682 organic food. It offers exporting countries, domestic retailers and policy makers new insights into 683 how organic consumers perceive imported organic products and why, providing valuable input to 684 their future export strategies. 


\section{References}

686

687

688

689

690

691

692

693

694

695

696

697

698

699

700

701

702

703

704

705

706

707

708

709

710

711

712

713

714

715

716

717

718

719

720

721

722

723

724

725

726

727

728

729
Ahmed, S. A., \& d'Astous, A. (2008). Antecedents, moderators and dimensions of country-of-origin evaluations. International Marketing Review, 25(1), 75-106.

Aschemann-Witzel, J., \& Zielke, S. (2017). Organic food prices and the consumer. A review of the research and open questions. Journal of Consumer Affairs, 51(1), 211-251. doi:10.1111/joca.12092

Balabanis, G., \& Diamantopoulos, A. (2004). Domestic country bias, country-of-origin effects, and consumer ethnocentrism: A multidimensional unfolding approach Journal of the Academy of Marketing Science, 32(1), 80-95. doi:10.1177/0092070303257644

BÖLW. (2017). Die Bio-Branche 2017 Retrieved from http://www.boelw.de/fileadmin/pics/Bio Fach 2017/ZDF 2017 Web.pdf

Bryman, A., \& Bell, E. (2015). Business Research Methods (4th ed.). Oxford: Oxford University Press.

Danmarks Statistik. (2017). Udenrigshandel med økologiske varer 2016: Importen af økologiske varer stiger kraftigt [International trade in organic products 2016: Import of organic goods rises sharply] (476). Retrieved from Copenhagen:

https://www.dst.dk/da/Statistik/nyt/NytHtml?cid=25782

Denzin, N. K. (2009). The research act: A theoretical introduction to sociological methods. New York, NY: Taylor \& Francis.

Dransfield, E., Ngapo, T. M., Nielsen, N. A., Bredahl, L., Sjödén, P. O., Magnusson, M., . . Nute, G. R. (2005). Consumer choice and suggested price for pork as influenced by its appearance, taste and information concerning country of origin and organic pig production. Meat Science, 69(1), 61-70. doi:10.1016/j.meatsci.2004.06.006

Feldmann, C., \& Hamm, U. (2015). Consumers' perceptions and preferences for local food: A review. Food Quality and Preference, 40, 152-164. doi:10.1016/j.foodqual.2014.09.014

Grebitus, C., Lusk, J. L., \& Nayga, R. M. (2013). Effect of distance of transportation on willingness to pay for food. Ecological Economics, 88(Supplement C), 67-75.

doi:https://doi.org/10.1016/j.ecolecon.2013.01.006

Greene, J. C., Caracelli, V. J., \& Graham, W. F. (1989). Toward a conceptual framework for mixedmethod evaluation designs. Educational Evaluation and Policy Analysis, 11(3), 255-274. doi:10.3102/01623737011003255

Hasselbach, J. L., \& Roosen, J. (2015). Motivations behind preferences for local or organic food. JOURNAL OF INTERNATIONAL CONSUMER MARKETING, 27, 295-306. doi:10.1080/08961530.2015.1022921

Hemmerling, S., Hamm, U., \& Spiller, A. (2015). Consumption behaviour regarding organic food from a marketing perspective-a literature review. Organic Agriculture, 1-37. doi:10.1007/s13165-015-0109-3

Hemmerling, S., Obermowe, T., Canavari, M., Sidali, K., Stolz, H., \& Spiller, A. (2013). Organic food labels as a signal of sensory quality - Insights from a cross-cultural consumer survey. Organic Agriculture, 3(1), 57-69. doi:10.1007/s13165-013-0046-y

Hempel, C., \& Hamm, U. (2016a). How important is local food to organic-minded consumers? Appetite, 96, 308-318. doi:10.1016/j.appet.2015.09.036

Hempel, C., \& Hamm, U. (2016b). Local and/or organic: a study on consumer preferences for organic food and food from different origins. International Journal of Consumer Studies, 40, 732-741. doi:10.1111/ijcs. 12288 
Herz, M. F., \& Diamantopoulos, A. (2012). Activation of country stereotypes: automaticity, consonance, and impact. Journal of the Academy of Marketing Science, 41(4), 400-417. doi:10.1007/s11747-012-0318-1

Hsieh, H.-F., \& Shannon, S. E. (2005). Three approaches to qualitative content analysis. Qualitative Health Research, 15(9), 1277-1288. doi:10.1177/1049732305276687

Hsieh, M.-H. (2004). An investigation of country-of-origin effect using correspondence analysis: a cross-national context. International Journal of Market Research, 46, 267-296.

Iyer, G. R., \& Kalita, J. K. (1997). The impact of country-of-origin and country-of-manufacture cues on consumer perceptions of quality and value. Journal of Global Marketing, 11(1), 728. doi:10.1300/J042v11n01 02

Josiassen, A., Lukas, B. A., Whitwell, G. J., \& Assaf, A. G. (2013). The halo model of origin images: Conceptualisation and initial empirical test. Journal of Consumer Behaviour, 12(4), 253-266. doi:10.1002/cb.1405

Kitzinger, J. (1994). The methodology of focus groups: the importance of interaction between research participants. Sociology of Health, 16(103-121).

Kledal, P. R., El-Naggar, A. H., Sirieix, L., \& Auersalmi, M. (2011). Organic food consumers' trade-offs between local or imported, conventional or organic products in the Egyptian metropolis of Cairo. African Journal of Business and Economic Research, 6(2 \& 3), 26-48.

Kotler, P., \& Gertner, D. (2002). Country as brand, product, and beyond: A place marketing and brand management perspective. Journal of Brand Management, 9, 249-261. doi:10.1057/palgrave.bm. 2540076

Krippendorff, K. (2004). Content Analysis: An introduction to its methodology (2nd ed.). Thousand Oaks: SAGE Publications Inc.

Lazzarini, G. A., Visschers, V. H. M., \& Siegrist, M. (2017). Our own country is best: Factors influencing consumers' sustainability perceptions of plant-based foods. Food Quality and Preference, 60, 165-177. doi:https://doi.org/10.1016/j.foodqual.2017.04.008

Liefeld, J. P. (2004). Consumer knowledge and use of country-of-origin information at the point of purchase. Journal of Consumer Behaviour, 4, 85-87. doi:10.1002/cb.161

Lincoln, Y. S., \& Guba, E. G. (1986). But is it rigorous? Trustworhiness and authenticity in naturalistic evaluation. New Directions for Program Evaluation, 73-84. doi:10.1002/ev.1427

Loebnitz, N., \& Aschemann-Witzel, J. (2016). Communicating organic food quality in China: Consumer perceptions of organic products and the effect of environmental value priming. Food Quality and Preference, 50, 102-108. doi:http://dx.doi.org/10.1016/j.foodqual.2016.02.003

Malhotra, N. K., Birks, D. F., \& Wills, P. (2012). Marketing Research: An Applied Approach (4th ed.). Harlow: Pearson Education Limited.

Manrai, L. A., Lascu, D.-N., \& Manrai, A. K. (1998). Interactive effects of country of origin and product category on product evaluations. International Business Review, 7, 591-615. doi:10.1016/s0969-5931(98)00026-2

Marian, L., \& Thøgersen, J. (2013). Direct and mediated impacts of product and process characteristics on consumers' choice of organic vs. conventional chicken. Food Quality and Preference, 29, 106-112. doi:http://dx.doi.org/10.1016/j.foodqual.2013.03.001

Moewius, J., Röhrig, P., \& Schaack, D. (Eds.). (2018). Zahlen • Daten • Fakten: Die Bio-Branche 2018. Berlin: Bund Ökologische Lebensmittelwirtschaft.

Newman, C. L., Turri, A. M., Howlett, E., \& Stokes, A. (2014). Twenty years of country-of-origin food labeling research: A review of the literature and implications for food marketing systems. Journal of Macromarketing, 34, 505-519. doi:10.1177/0276146714529306 
Nuttavuthisit, K., \& Thøgersen, J. (2017). The importance of consumer trust for the emergence of a market for green products: The case of organic food. Journal of Business Ethics, 140, 323337.

Nuttavuthisit, K., \& Thøgersen, J. (2018). Why do consumers in developing countries prefer imported products? The case of organic food in Thailand. Asia Pacific Journal of Marketing and Logistics(Forthcoming).

Onozaka, Y., \& Mcfadden, D. T. (2011). Does local labeling complement or compete with other sustainable labels? A conjoint analysis of direct and joint values for fresh produce claim. American Journal of Agricultural Economics, 93, 693-706.

Ortega, D. L., Hong, S. J., Wang, H. H., \& Wu, L. (2016). Emerging markets for imported beef in China: Results from a consumer choice experiment in Beijing. Meat Science, 121, 317-323. doi:http://dx.doi.org/10.1016/j.meatsci.2016.06.032

Pabst, J., \& Dietz, C. (2014). Der unerbitterliche Kampf der Bio-Giganten. Die Welt. Retrieved from http://www.welt.de/wirtschaft/article132212414/Der-unerbittliche-Kampf-der-BioGiganten.html

Padel, S., \& Foster, C. (2005). Exploring the gap between attitudes and behaviour: Understanding why consumers buy or do not buy organic food British Food Journal, 107(8), 606-625. doi:12048/10.1108/00070700510611002

Pharr, J. M. (2005). Synthesizing Country-of-Origin Research from the Last Decade: Is the Concept Still Salient in an Era of Global Brands? Journal of Marketing Theory and Practice, 13(4), 34-45.

Rosenbloom, A., \& Haefner, J. E. (2009). Country-of-origin effects and global brand trust: A first look. Journal of Global Marketing, 22, 267-278.

Roth, K. P., \& Diamantopoulos, A. (2009). Advancing the country image construct. Journal of Business Research, 62, 726-740. doi:10.1016/j.jbusres.2008.05.014

Sahota, A. (2018). The global market for organic food \& drink. In H. Willer \& J. Lernoud (Eds.), The world of organic agriculture. Statistics and emerging trends 2018 (pp. 145-150). Bonn: Research Institute of Organic Agriculture (FiBL) and IFOAM - Organics International.

Schjøll, A. (2017). Country-of-origin preferences for organic food. Organic Agriculture, 7, 315327. doi:10.1007/s13165-016-0159-1

Sirieix, L., Kledal, P. R., \& Sulitang, T. (2011). Organic food consumers' trade-offs between local or imported, conventional or organic products: a qualitative study in Shanghai : Local and imported organic product. International Journal of Consumer Studies, 35(6), 670-678. doi:10.1111/j.1470-6431.2010.00960.x

Tagesspiegel, D. (2015). Wer ist der Größte unter den Supermärkten? . Der Tagesspiegel. Retrieved from http://www.tagesspiegel.de/wirtschaft/edeka-aldi-lidl-und-co-wer-ist-dergroesste-unter-den-supermaerkten/11500488.html

Thøgersen, J. (2011). Green shopping: For selfish reasons or the common good? American Behavioral Scientist, 55, 1052 - 1076.

Thøgersen, J., Pedersen, S., \& Aschemann-Witzel, J. (2018). The impact of organic certification and country of origin on consumer food choice in developed and emerging economies. Food Quality and Preference(Forthcoming).

Thøgersen, J., Pedersen, S., Paternoga, M., Schwendel, E., \& Aschemann-Witzel, J. (2017). How important is country-of-origin for organic food consumers? A review of the literature and suggestions for future research. British Food Journal, 119(3), 542-557. doi:10.1108/BFJ-092016-0406 
824 Tobler, C., Visschers, V. H. M., \& Siegrist, M. (2011). Organic tomatoes versus canned beans:

825

826

827

828

829

830

831

832

833

834

835

836

837

838

839 How do consumers assess the environmental friendliness of vegetables? Environment and Behavior, 43(5), 591-611.

Usunier, J.-C., \& Cestre, G. (2007). Product Ethnicity: Revisiting the Match between Products and Countries. Journal of International Marketing, 15(3), 32-72. doi:10.1509/jimk.15.3.32

Verlegh, P. W. J., \& Steenkamp, J.-B. E. M. (1999). A review and meta-analysis of country-oforigin research. Journal of Economic Psychology, 20, 521-546. doi:10.1016/s01674870(99)00023-9

Willer, H., \& Lernoud, J. (Eds.). (2018). The world of organic agriculture. Statistics and emerging trends 2018. Bonn: Research Institute of Organic Agriculture (FiBL) and IFOAM Organics International.

Xie, J., Gao, Z., Swisher, M., \& Zhao, X. (2016). Consumers' preferences for fresh broccolis: Interactive effects between country of origin and organic labels. Agricultural Economics, 47, 181-191. doi:10.1111/agec.12193 
840 Table 1. Socio-demographic characteristics of in-store informants, overall and by city and 841 retail chain

\begin{tabular}{|c|c|c|c|c|c|c|c|}
\hline & \multirow[b]{2}{*}{ Overall } & \multicolumn{2}{|c|}{ Hamburg } & \multicolumn{2}{|c|}{ Munich } & \multicolumn{2}{|c|}{ Münster } \\
\hline & & Denn's & Rewe & Denn's & Rewe & Denn's & Rewe \\
\hline Number of interviews & 255 & 59 & 34 & 49 & 32 & 52 & 29 \\
\hline \multicolumn{8}{|l|}{ Gender } \\
\hline Female, \% & 68 & 78 & 50 & 67 & 59 & 73 & 69 \\
\hline Male, \% & 32 & 22 & 50 & 33 & 41 & 27 & 31 \\
\hline \multicolumn{8}{|l|}{ Age } \\
\hline Mean & 45 & 45 & 41 & 46 & 50 & 43 & 49 \\
\hline SD & 14 & 12 & 14 & 13 & 16 & 14 & 17 \\
\hline Youngest & 21 & 23 & 26 & 24 & 22 & 21 & 22 \\
\hline Oldest & 84 & 72 & 80 & 75 & 84 & 73 & 77 \\
\hline \multicolumn{8}{|l|}{ Household size } \\
\hline Mean & 2,3 & 2,1 & 2,4 & 2,1 & 2,7 & 2,5 & 2,6 \\
\hline SD & 1,1 & 0,7 & 1,1 & 1,1 & 1,2 & 1,05 & 1,8 \\
\hline \multicolumn{8}{|l|}{ Education } \\
\hline University degree & $64 \%$ & $66 \%$ & $65 \%$ & $71 \%$ & $53 \%$ & $58 \%$ & $66 \%$ \\
\hline Apprenticeship & $11 \%$ & $5 \%$ & $9 \%$ & $8 \%$ & $25 \%$ & $13 \%$ & $7 \%$ \\
\hline Secondary school (Abitur) & $18 \%$ & $19 \%$ & $15 \%$ & $14 \%$ & $16 \%$ & $25 \%$ & $14 \%$ \\
\hline Lower than secondary school & $8 \%$ & $10 \%$ & $12 \%$ & $6 \%$ & $3 \%$ & $4 \%$ & $14 \%$ \\
\hline None & $0 \%$ & $0 \%$ & $0 \%$ & $0 \%$ & $3 \%$ & $0 \%$ & $0 \%$ \\
\hline \multicolumn{8}{|c|}{ Organic purchases (vs. conventional) } \\
\hline Mean (scale 1-5) & 4,1 & 4,2 & 3,8 & 4,1 & 4,0 & 4,3 & 4,1 \\
\hline Rarely (1) & $2 \%$ & $2 \%$ & $3 \%$ & $4 \%$ & $3 \%$ & $0 \%$ & $0 \%$ \\
\hline Sometimes (2) & $5 \%$ & $8 \%$ & $9 \%$ & $4 \%$ & $6 \%$ & $0 \%$ & $3 \%$ \\
\hline Equally (3) & $18 \%$ & $10 \%$ & $29 \%$ & $16 \%$ & $19 \%$ & $17 \%$ & $24 \%$ \\
\hline Quite often (4) & $29 \%$ & $29 \%$ & $24 \%$ & $20 \%$ & $28 \%$ & $37 \%$ & $34 \%$ \\
\hline Always (5) & $45 \%$ & $47 \%$ & $35 \%$ & $51 \%$ & $44 \%$ & $46 \%$ & $38 \%$ \\
\hline No information & $2 \%$ & $3 \%$ & $0 \%$ & $4 \%$ & $0 \%$ & $0 \%$ & $0 \%$ \\
\hline \multicolumn{8}{|l|}{ Interview shelf } \\
\hline Vegetables & $46 \%$ & $40 \%$ & $44 \%$ & $39 \%$ & $44 \%$ & $60 \%$ & $55 \%$ \\
\hline Dairy & $40 \%$ & $41 \%$ & $38 \%$ & $41 \%$ & $50 \%$ & $32 \%$ & $38 \%$ \\
\hline Meat & $14 \%$ & $19 \%$ & $18 \%$ & $20 \%$ & $6 \%$ & $8 \%$ & $7 \%$ \\
\hline
\end{tabular}


843 Table 2. Importance of and attention to COO and reasons for preferring geographically close

844 COOs (in-store interviews, overall/per city/stores)

\begin{tabular}{|c|c|c|c|c|c|c|}
\hline & $\begin{array}{l}\text { Overall } \\
(n=255)\end{array}$ & $\begin{array}{c}\text { Hamburg } \\
(\mathbf{n}=93)\end{array}$ & $\begin{array}{c}\text { Münster } \\
(\mathbf{n}=\mathbf{8 1})\end{array}$ & $\begin{array}{c}\text { Munich } \\
(\mathrm{n}=\mathbf{8 1})\end{array}$ & Rewe & denn's \\
\hline \multicolumn{7}{|l|}{ Importance of $\mathrm{COO}$} \\
\hline Matters & $76 \%$ & $69 \%$ & $79 \%$ & $81 \%$ & $64 \%$ & $83 \%$ \\
\hline Sometimes & $8 \%$ & $11 \%$ & $5 \%$ & $7 \%$ & $8 \%$ & $7 \%$ \\
\hline Does not matter & $16 \%$ & $20 \%$ & $16 \%$ & $12 \%$ & $27 \%$ & $10 \%$ \\
\hline \multicolumn{7}{|l|}{ Attention to $\mathrm{COO}$} \\
\hline Always & $37 \%$ & $27 \%$ & $33 \%$ & $52 \%$ & $33 \%$ & $39 \%$ \\
\hline Sometimes & $27 \%$ & $32 \%$ & $25 \%$ & $23 \%$ & $21 \%$ & $31 \%$ \\
\hline Inferred & $11 \%$ & $11 \%$ & $15 \%$ & $6 \%$ & $9 \%$ & $11 \%$ \\
\hline No & $23 \%$ & $27 \%$ & $26 \%$ & $16 \%$ & $36 \%$ & $16 \%$ \\
\hline n.a. & $2 \%$ & $3 \%$ & $1 \%$ & $2 \%$ & $1 \%$ & $3 \%$ \\
\hline \multicolumn{7}{|l|}{$\begin{array}{l}\text { Reasons for geographical } \\
\text { preference }\end{array}$} \\
\hline Short haulage distance & $72 \%$ & $88 \%$ & $58 \%$ & $74 \%$ & $74 \%$ & $70 \%$ \\
\hline Trust in standards & $24 \%$ & $18 \%$ & $38 \%$ & $10 \%$ & $21 \%$ & $25 \%$ \\
\hline Country image & $11 \%$ & $3 \%$ & $8 \%$ & $21 \%$ & $5 \%$ & $14 \%$ \\
\hline Personal preferences & $9 \%$ & $3 \%$ & $8 \%$ & $15 \%$ & $12 \%$ & $7 \%$ \\
\hline Special products & $7 \%$ & $15 \%$ & $4 \%$ & $5 \%$ & $5 \%$ & $9 \%$ \\
\hline Product-country match & $7 \%$ & $12 \%$ & $4 \%$ & $5 \%$ & $7 \%$ & $6 \%$ \\
\hline Food culture & $6 \%$ & $12 \%$ & $6 \%$ & $0 \%$ & $10 \%$ & $4 \%$ \\
\hline Taste preferences & $5 \%$ & $9 \%$ & $6 \%$ & $0 \%$ & $7 \%$ & $4 \%$ \\
\hline Animal welfare & $4 \%$ & $12 \%$ & $0 \%$ & $3 \%$ & $0 \%$ & $6 \%$ \\
\hline Support of country & $2 \%$ & $3 \%$ & $0 \%$ & $3 \%$ & $0 \%$ & $2 \%$ \\
\hline
\end{tabular}

$845{ }^{1}$ In Hamburg, a total of 118 reasons were mentioned by 93 participants, in Munich 132 reasons were mentioned by 81 participants 846 and in Münster, 106 reasons by 81 participants. The percentages show the share of participants mentioning a particular reason. 
847 Table 3. Socio-demographic characteristics of focus group participants

\begin{tabular}{lcccccc}
\hline & \multicolumn{2}{c}{ Hamburg } & \multicolumn{2}{c}{ Munich } & \multicolumn{2}{c}{ Münster } \\
\hline & $\begin{array}{c}\text { Focus } \\
\text { group 1 }\end{array}$ & $\begin{array}{c}\text { Focus } \\
\text { group 2 }\end{array}$ & $\begin{array}{c}\text { Focus } \\
\text { group 1 }\end{array}$ & $\begin{array}{c}\text { Focus } \\
\text { group 2 }\end{array}$ & $\begin{array}{c}\text { Focus } \\
\text { group 1 }\end{array}$ & $\begin{array}{c}\text { Focus } \\
\text { group 2 }\end{array}$ \\
\hline Number of participants & 7 & 7 & 6 & 6 & 7 & 5 \\
\hline Female/Male & $6 / 1$ & $4 / 3$ & $3 / 3$ & $4 / 2$ & $5 / 2$ & $2 / 3$ \\
\hline Age & & & & & & \\
Mean & 37 & 33 & 36 & 33 & 31 & 43 \\
Youngest & 22 & 24 & 23 & 25 & 21 & 25 \\
Oldest & 70 & 55 & 65 & 58 & 51 & 55 \\
\hline Occupation & 3 & 2 & 3 & 3 & 5 & \\
Student & 3 & 5 & 2 & 3 & 2 & 3 \\
Employed & 1 & - & 1 & - & - & - \\
Retired & - & - & - & - & & - \\
Unemployed & & & & & & \\
\hline
\end{tabular}

848 
Table 4: Evaluation of three target countries across focus groups*

\begin{tabular}{|c|c|c|c|c|c|c|}
\hline \multirow[t]{2}{*}{ City/country } & \multicolumn{2}{|c|}{ Denmark } & \multicolumn{2}{|r|}{ Austria } & \multicolumn{2}{|c|}{ The Netherlands } \\
\hline & $\begin{array}{l}\text { Overall } \\
\text { ranking }\end{array}$ & Justification & $\begin{array}{l}\text { Overall } \\
\text { ranking }\end{array}$ & Justification & $\begin{array}{l}\text { Overall } \\
\text { ranking }\end{array}$ & Justification \\
\hline Hamburg & 0 & $\begin{array}{l}\text { Refugee policies (-) } \\
\text { Border control (-) } \\
\text { Expensive }(-) \\
\text { Liberal society }(+) \\
\text { Fair social system }(+) \\
\text { Lack of interest }(0) \\
\text { Lack of knowledge }(0)\end{array}$ & 0 & $\begin{array}{l}\text { Refugee policies (-) } \\
\text { Hostile to foreigners (-) } \\
\text { Conservative }(-) \\
\text { Food culture }(+) \\
\text { Nature }(+) \\
\text { Lack of knowledge }(0)\end{array}$ & ++ & $\begin{array}{l}\text { Right-wing politics }(-) \\
\text { Liberal society }(+) \\
\text { Multi-cultural }(+) \\
\text { Friendly people }(+) \\
\text { Fair social system }(+) \\
\text { Lack of knowledge }(0)\end{array}$ \\
\hline Munich & + & $\begin{array}{l}\text { Refugee policies (-) } \\
\text { Ecological image }(+) \\
\text { Fair social system }(+) \\
\text { Nature }(+) \\
\text { Lack of knowledge }(0)\end{array}$ & ++ & $\begin{array}{l}\text { Refugee policies }(-) \\
\text { Nature }(+) \\
\text { Ecological image }(+) \\
\text { Friendly people }(+) \\
\text { Culture }(+)\end{array}$ & + & $\begin{array}{l}\text { Refugee policies }(-) \\
\text { Ecological image }(+) \\
\text { Friendly people }(+) \\
\text { Multi-cultural }(+)\end{array}$ \\
\hline Münster & + & $\begin{array}{l}\text { Fair social system }(+) \\
\text { Culture }(+) \\
\text { Lack of knowledge }(0)\end{array}$ & ++ & $\begin{array}{l}\text { Hostile to foreigners (-) } \\
\text { Friendly people }(+) \\
\text { Food culture }(+) \\
\text { Nature }(+) \\
\text { Lack of knowledge }(0)\end{array}$ & + & $\begin{array}{l}\text { Liberal society }(+) \\
\text { Multi-cultural }(+) \\
\text { Friendly people }(+) \\
\text { Nature }(+) \\
\text { Ecological image }(+)\end{array}$ \\
\hline
\end{tabular}

* Median of all country evaluations in focus groups per city based on this scale:

\begin{tabular}{|l|l|l|l|l|l|l|}
\hline+++ & ++ & + & 0 & - & -- & $85--$ \\
\hline 10 & $9-8$ & 7 & $6-5$ & 4 & $3-2$ & $51-0$ \\
\hline
\end{tabular}


852 Figure 1. German consumers' preferred CsOO (percentage of in-store participants stating at 853 least one preferred country, overall/per city, excluding consumers with no preferences or 854 unspecific preferences such as Europe)

855

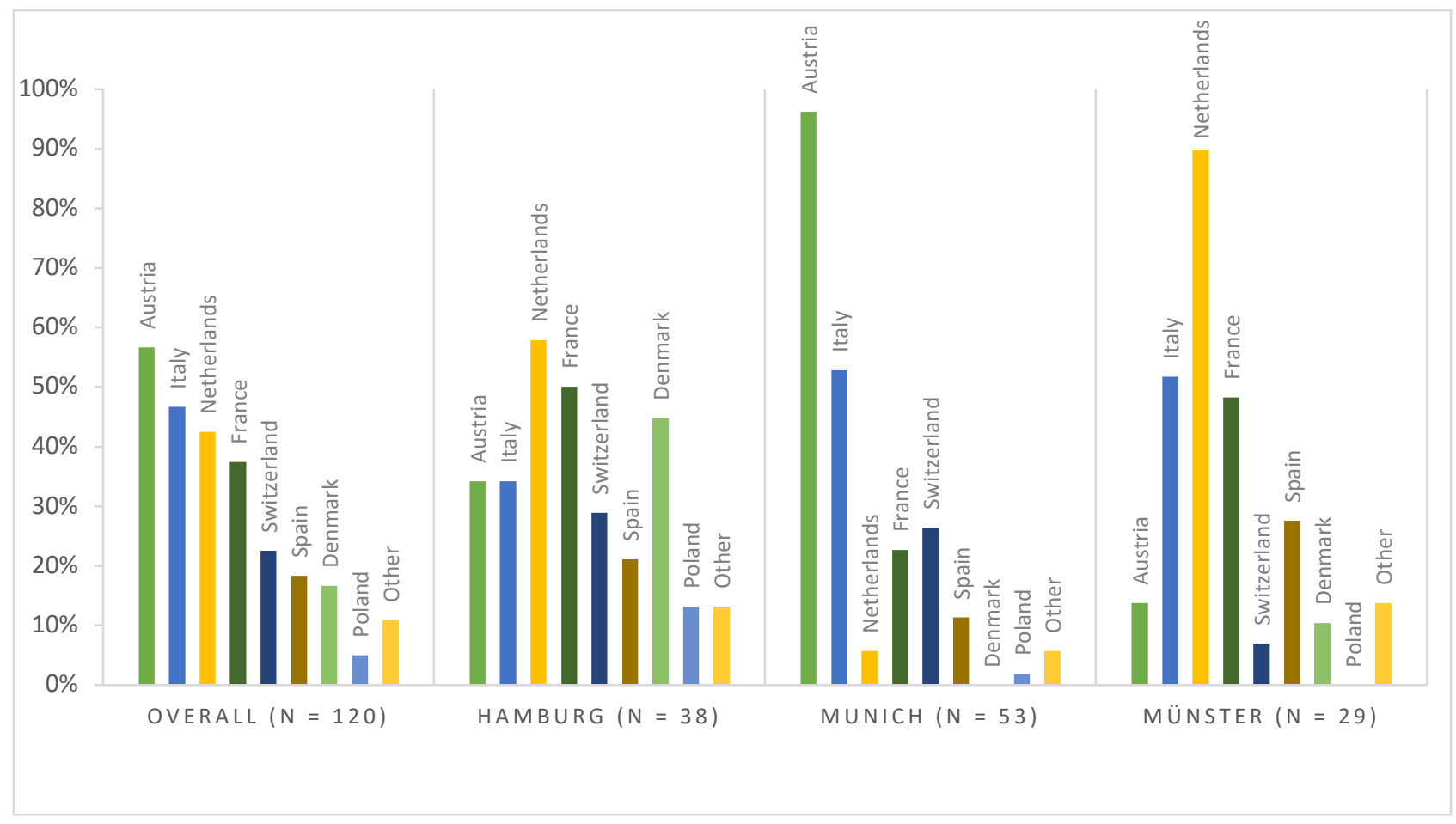


865 Appendix A: Map over Germany and the studied neighbouring countries 866 867

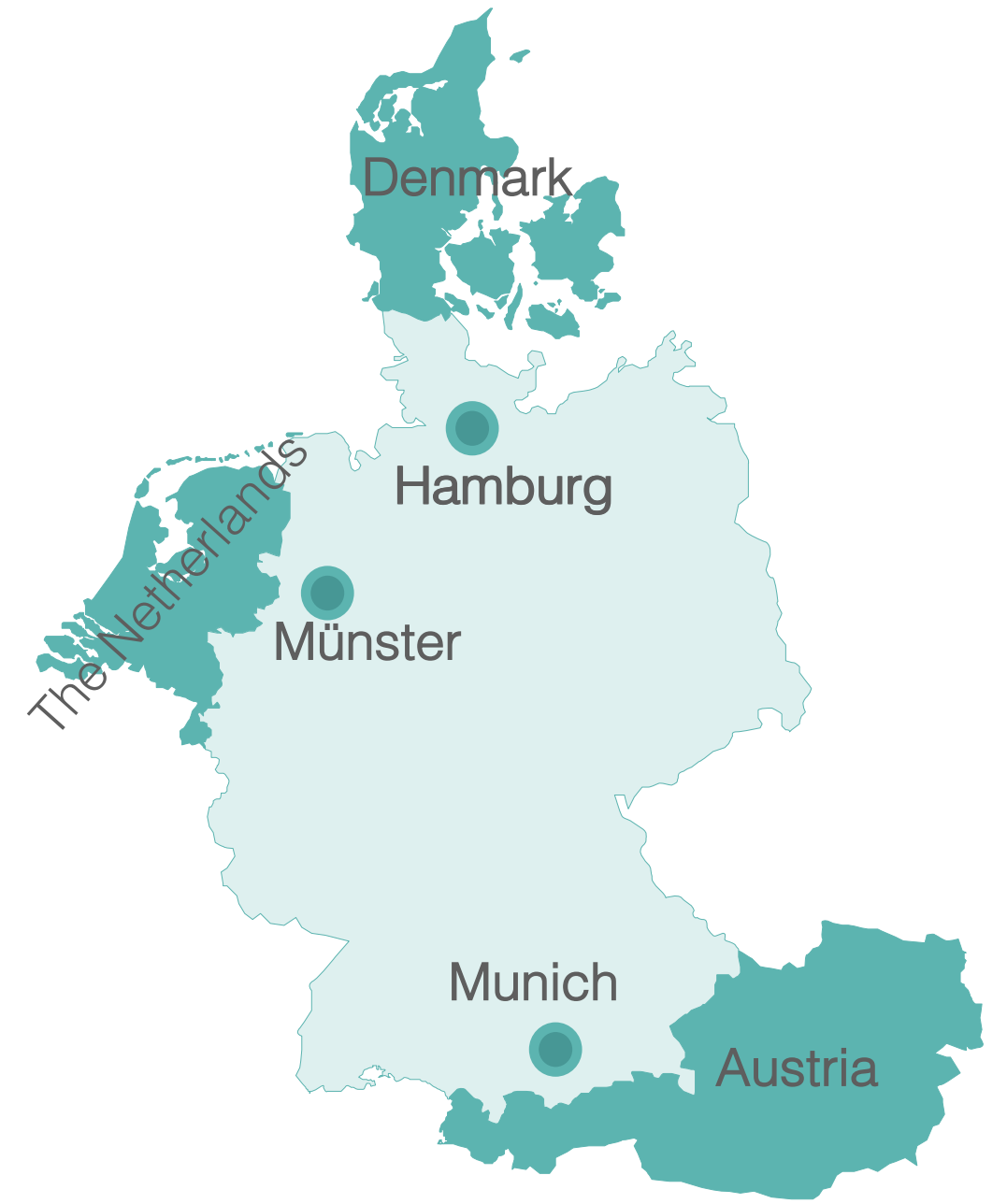

